\title{
On-body Cavity-Backed Low-UWB Antenna for Capsule Localization
}

\author{
Chaïmaâ Kissi ${ }^{1} \cdot$ Mariella Särestöniemi $^{2} \cdot$ Timo Kumpuniemi $^{2}$ - $\cdot$ Marko Sonkki $^{2} \cdot$ Sami Myllymäki $^{3}$. \\ Mohamed Nabil Srifi ${ }^{1}$. Carlos Pomalaza-Raez ${ }^{4}$
}

Received: 4 March 2019 / Revised: 5 September 2019 / Accepted: 23 September 2019 / Published online: 30 September 2019

(c) The Author(s) 2019

\begin{abstract}
The paper presents a novel antenna operating at the lower UWB band (3.75-4.25 GHz), defined originally in IEEE 802.15.6 standard for Body Area Networks (BAN) applications. The proposed antenna is designed for biomedical application, wireless capsule endoscopy localization. In other words, the concerned application is dedicated to track a capsule, by means of an external device, swallowed by the patient to provide captured images of the Small Intestine (SI), essential part of the GastroIntestinal (GI) tract, and transfer them in real-time to the external device. In this context, antenna with and without cavity-backed structures, are presented and compared with the requirements for a receiving antenna in terms of directivity and bandwidth coverage in question. It was revealed that the cavity approach improved the antenna gain up to $8 \mathrm{dBi}$, at the $4 \mathrm{GHz}$ center frequency, compared to $6 \mathrm{dBi}$ without the cavity presence. Simulations were carried out using CST Microwave Studio, and the results were validated by measurements in proximity to human body. The antenna safety issue was assessed with CST SAR (Specific Absorption Rate) calculation, in compliance with IEEE/IEC 62704-1 standard. Results showed a maximum SAR of $0.112 \mathrm{~W} / \mathrm{kg}$ and $0.005 \mathrm{~W} / \mathrm{kg}$ at $4 \mathrm{~mm}$ and $30 \mathrm{~mm}$ antenna-skin distance, in the range of the SAR limit guidelines defined by safety standards. The cavity-backed antenna ability to penetrate the human tissues, to reach the small intestine layer was studied by means of CST voxel model and compared to a multi-layer model emulating the dielectric properties of the human tissues at $4 \mathrm{GHz}$. This analysis was conducted using power flow results and completed by the power field probes at the several tissue interfaces.
\end{abstract}

Keywords BAN · IEEE 802.15.6 standard · High gain · Small-intestine · WBAN · Capsule

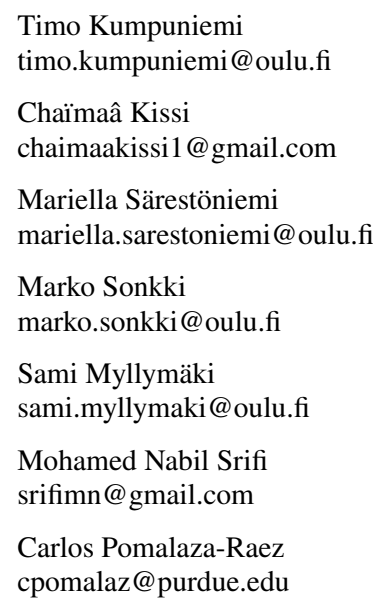

1 Electronics and Telecommunication Systems Research Group, National School of Applied Sciences (ENSA), Ibn Tofail University, Kenitra, Morocco

2 Centre for Wireless Communications, Faculty of Information Technology and Electrical Engineering, University of Oulu, Oulu, Finland

3 Microelectronics Research Unit, Faculty of Information Technology and Electrical Engineering, University of Oulu, Oulu, Finland

4 Department of Electrical and Computer Engineering, Purdue University, Fort Wayne, IN 46805, USA 


\section{Introduction}

Wearable antennas are in the interest of several novel applications [1-3]. Their involvement is significant, in particular in medical applications [4]. In this context, Wireless Body Area Networks (WBAN) comes to provide consistent guidelines to meet the scientific requirements [5]. One of them appealing to these antennas is wireless capsule endoscopy (WCE) localization [6, 7], since it requires an efficient designed on-body antenna to track the capsule movement inside the GastroIntestinal (GI) tract, in particular SmallIntestine (SI), of a patient [8]. The main focus is to have a directional antenna by maintaining its features, in terms of the covered bandwidth in close proximity to a human body (abdomen area) and to have the ability to reach the small intestine tissue. Last decades, many works have been oriented towards this kind of research topic by using different frequency ranges $[9,10]$. However, the low Ultra Wideband (UWB) band (3.75-4.25 GHz) is defined originally in IEEE 802.15.6 standard [11-13] and it is preferred to minimize the path loss caused by lossy human body tissues. Additionally, to improve the image resolution quality, the requirement is to assess the captured images from inside the small intestine. Thus, transfer them wirelessly in real-time to external devices is a crucial question, as discussed in [6]. Besides, in literature, several channel models were defined and investigated with the focus on the specific frequency range studied in this paper.

The aim of the paper is to further discuss a lately published antenna, operating at low UWB band, according to IEEE 802.15.6 standard. The structure is intended to wireless capsule endoscopy localization purposes. The paper defines the antenna designed according to two structures, single and cavity-backed antennas, presented in Sect. 2. On-body investigations using both antennas structures are provided in Sect. 3. Last section presents different perspectives of the present work. Simulations were carried out by using CST Microwave Studio, and validated in free-space and on-body study cases by measurements. The detailed investigations confirm a good suitability of the proposed cavity-backed antenna structure for the WCE localization.

\section{Antenna Structure and Configuration Analysis}

\subsection{Simulation Results}

This section presents an extended configuration analysis of a recently published UWB antenna [14], by distinguishing two approaches: Planar and cavity-backed antenna structures.
The published work demonstrates that both antennas are directive and working at the low UWB band defined in IEEE 802.15.6 standard for WBAN applications.

As discussed in details in [14], a planar antenna was built at first stage, to which a cavity was introduced to back the planar antenna structure. The parametric configuration of the single antenna and its emplacement inside the cavity is detailed in Figs. 1 and 2 and the detailed parameter values are summarized in Table 1.

The main idea of including the cavity was to deviate the antenna radiation from $\mathrm{Y}$-axis to $\mathrm{Z}$-axis and further increase the antenna directivity to fit realistic scenario where the antennas are installed on the human body. For this aim, a metallic box of $0.5 \mathrm{~mm}$-thickness acting as reflector was backing the planar antenna structure. The antenna was placed in the center of the cavity and its dimensions were discussed in [14]. The cavity overall size is $90.8 \mathrm{~mm}$

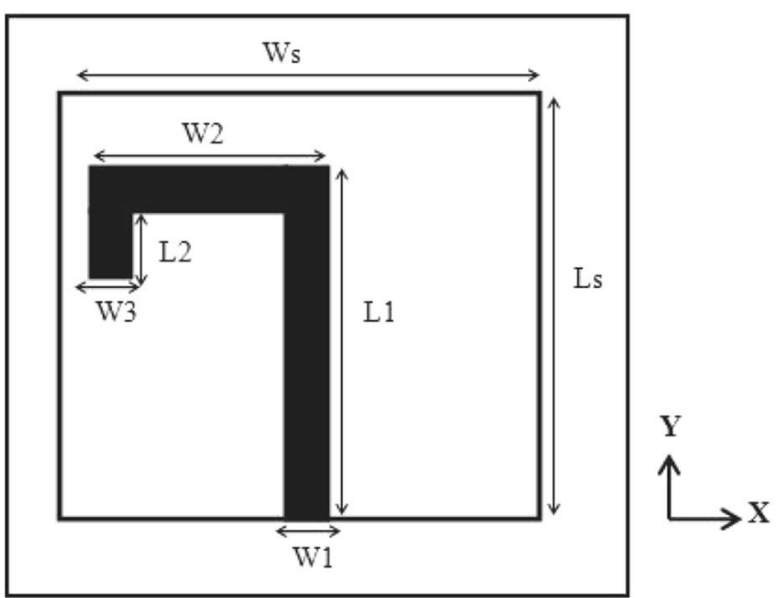

(a)

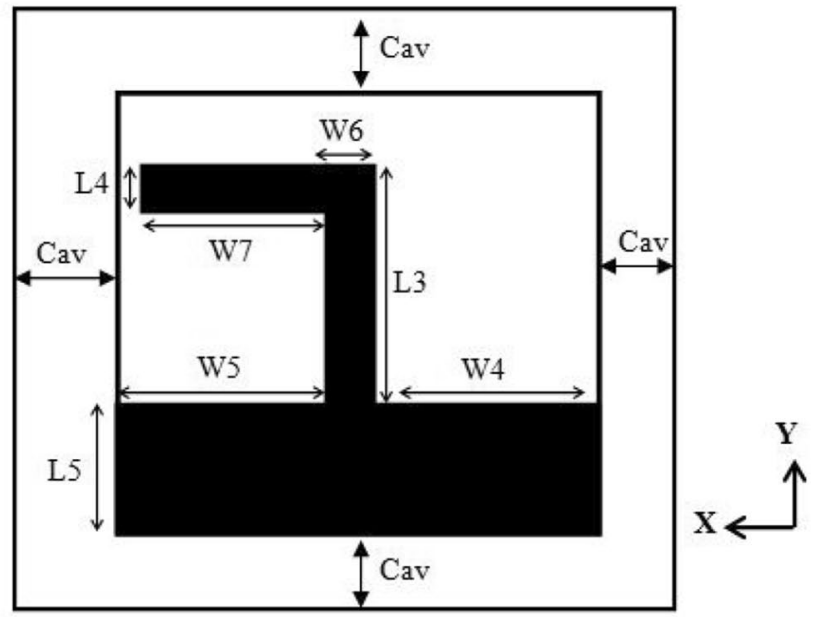

(b)

Fig. 1 a Front and $\mathbf{b}$ back sides of the proposed UWB cavity-backed antenna 
Table 1 Parametric details of the cavity-backed antenna

\begin{tabular}{llll}
\hline Parameter & Value $(\mathrm{mm})$ & Parameter & Value $(\mathrm{mm})$ \\
\hline Ws & 30.3 & W6 & 4 \\
Ls & 25 & W7 & 9.5 \\
hs & 1.6 & L1 & 20.14 \\
W1 & 3 & L2 & 2.9 \\
W2 & 16.4 & L3 & 12 \\
W3 & 3 & L4 & 2 \\
W4 & 13.15 & L5 & 7.14 \\
W5 & 13.15 & Cav & 30 \\
\hline
\end{tabular}

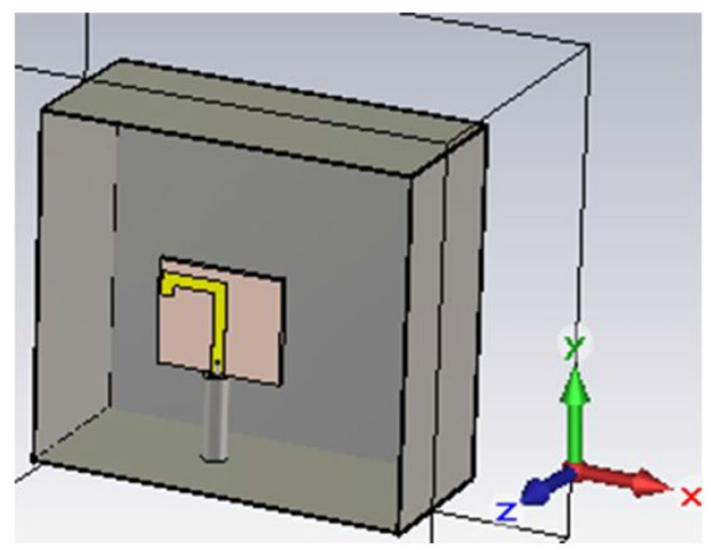

Fig. 2 The UWB cavity-backed built model and fed by coaxial cable in CST

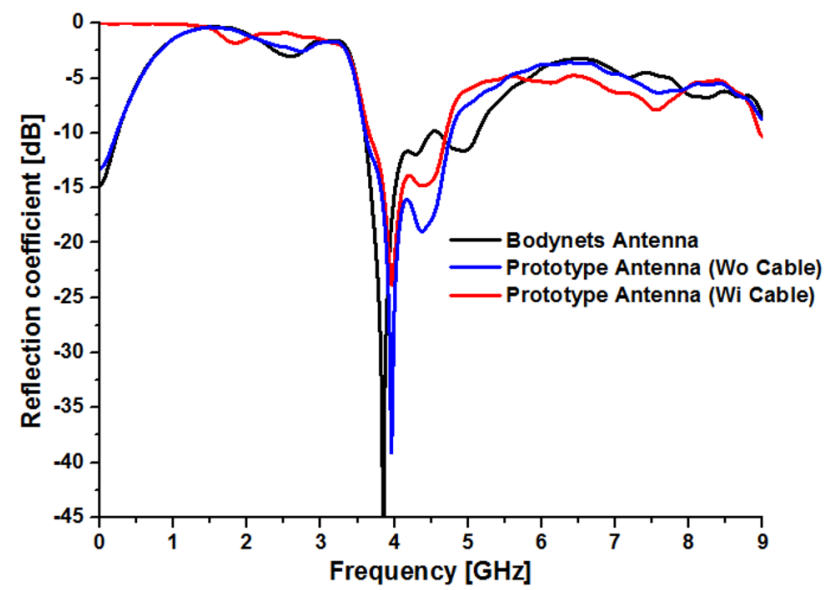

Fig. 3 Simulated reflection coefficient of the UWB cavity-backed antenna

(length), $86 \mathrm{~mm}$ (width) and $39.5 \mathrm{~mm}$ (height). In [14], both antenna structures were fed by directly connecting a waveguide port to the microstrip line. The planar antenna was embedded in the center of the cavity, as presented originally

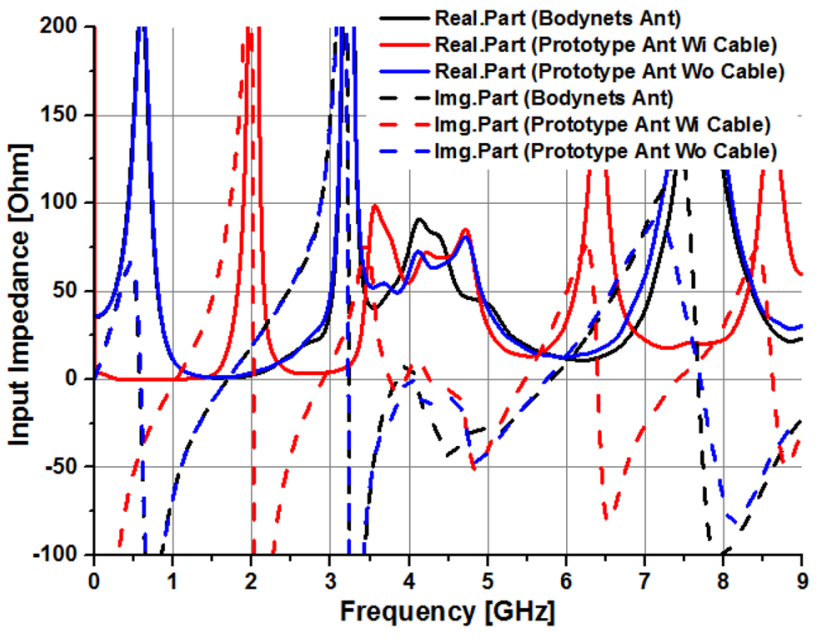

Fig. 4 Simulated input impedance of UWB cavity-backed antenna

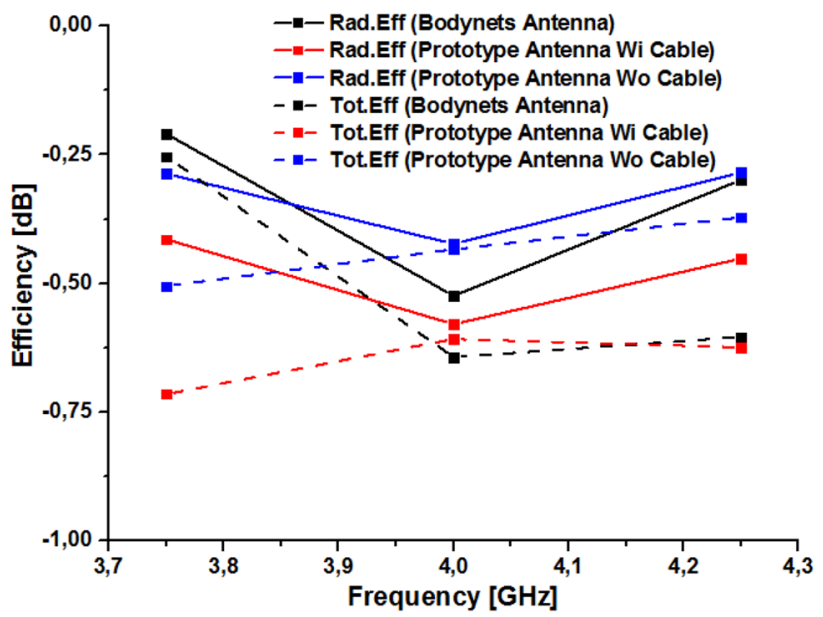

Fig. 5 Simulated efficiency of UWB cavity-backed antenna

in [14]. This designed antenna had a simulated bandwidth of $3.61-4.46 \mathrm{GHz}$, and resonated at $3.85 \mathrm{GHz}$ with $-50.72 \mathrm{~dB}$ return loss, as presented in Fig. 3 by "Bodynets Antenna" plot. However, for this initial built model, the antenna input impedance was $71.82+\mathrm{j} 9.46 \Omega$, as shown in Fig. 4, which is unsuitable to practical case. Later, by positioning the antenna on the cavity surface, with a distance about the cavity height of $30 \mathrm{~mm}$, the upper frequency was increased to $4.76 \mathrm{GHz}$, as presented and known under the name "Prototype Antenna (Wo Cable)", in Fig. 3. For this case, the antenna resonant frequency was shifted upwards to $3.96 \mathrm{GHz}$ with a return loss of $-39.12 \mathrm{~dB}$ and the antenna input impedance was slightly modified to $63.35+\mathrm{j} 0.83 \Omega$. However, by applying a coaxial cable to feed the antenna, named "Prototype Antenna Wi cable" in Figs. 3, 4, 5 and 6, the $-10 \mathrm{~dB}$ impedance bandwidth and the resonant frequency remain quite the 


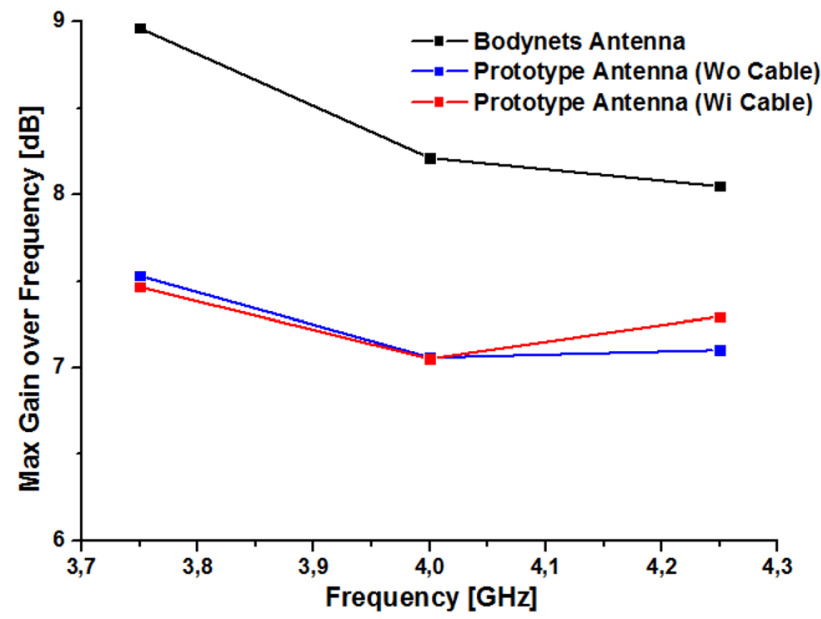

Fig. 6 Simulated maximum gain over frequency of the UWB cavitybacked antenna

same about $3.66-4.70 \mathrm{GHz}$ and $3.97 \mathrm{GHz}$, respectively. The only difference is that the maximum return loss is decreased to $-23.84 \mathrm{~dB}$ as shown in Fig. 3. It was concluded that, the input impedance is close to realistic case where the antenna is measured appealing to $50 \Omega$ coaxial cable in order to connect the antenna to the measurement equipment, as presented in Fig. 4.

The cavity-backed antenna was predicted to radiate well over the frequency band under interest, as shown in Fig. 5. Additionally, from Fig. 6 is it clearly seen that the antenna maximum gain is stable over the studied frequency range, within the range of $8-9 \mathrm{dBi}$ and $7-8 \mathrm{dBi}$ for the case the antenna is placed inside the cavity "Bodynets Antenna" and at the cavity surface "Prototype Antenna (Wo Cable)", respectively. It seems that the distance of the antenna from the cavity bottom has an impact on the reached gain.

One can conclude, as the distance separating the antenna ground plane to the cavity bottom increases, the gain decreases. However, the cable feeding does not have any effect which is good seen from practical point of view. The cavity-backed antenna has a good directivity slightly towards $\mathrm{Z}$-axis with main values of $7.88 \mathrm{dBi}, 7.63 \mathrm{dBi}$ and $7.75 \mathrm{dBi}$ at $3.75 \mathrm{GHz}, 4 \mathrm{GHz}$ and $4.25 \mathrm{GHz}$, respectively, as illustrated in Fig. 7.

\subsection{Measurement Results}

The cavity-backed antenna structure was prototyped and measured, as demonstrated in Fig. 8a, b. The reflection coefficient of the cavity-backed antenna was compared in Fig. 9 for the three previously listed antenna cases. Reported results show that the maximum measured reflection coefficient in free-space is $-17 \mathrm{~dB}$ at $4 \mathrm{GHz}$ with a covered $-10 \mathrm{~dB}$ impedance bandwidth matching of $3.75-4.26 \mathrm{GHz}$.

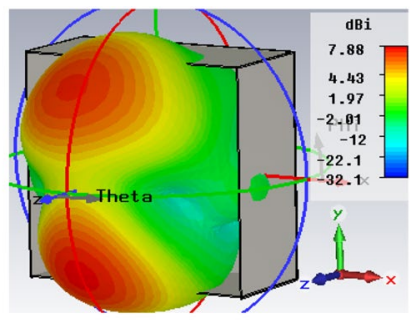

(a)

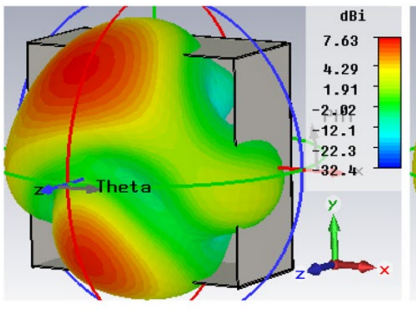

(b)

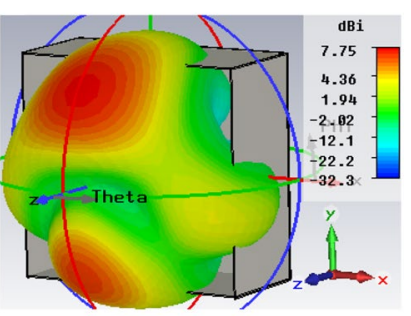

(c)
Fig. 7 Simulated 3D directivity of the UWB cavity-backed antenna at a $3.75 \mathrm{GHz}$ b $4 \mathrm{GHz}$ and $\mathbf{c} 4.25 \mathrm{GHz}$

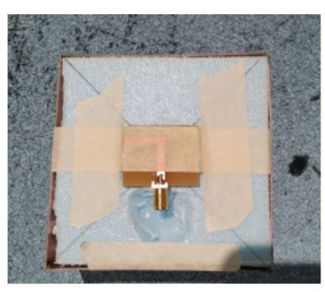

(a)

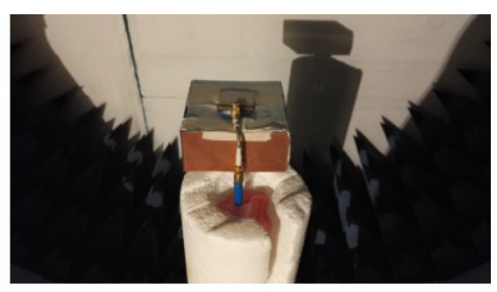

(b)
Fig. 8 a Antenna prototype and b Measurement setup

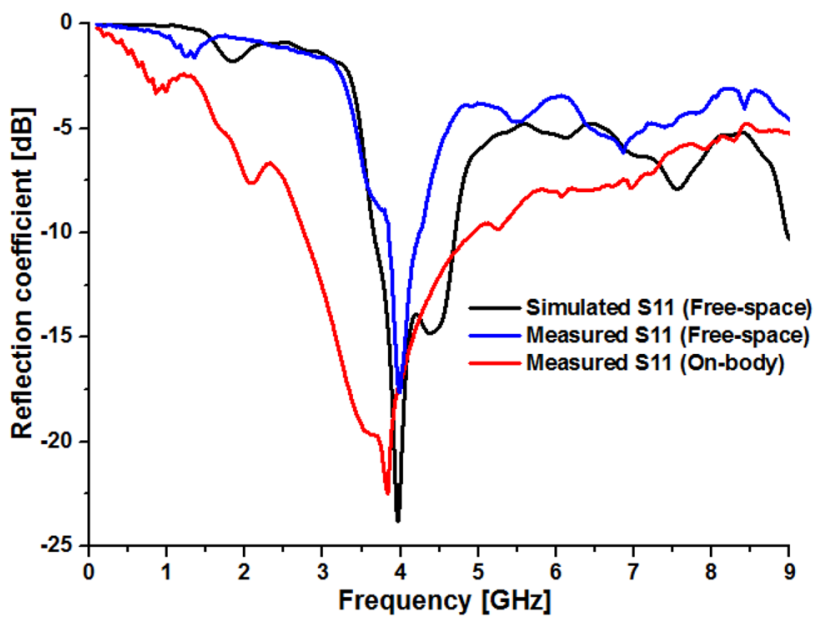

Fig. 9 Measured reflection coefficient comparison of the UWB cavity-backed antenna

The antenna was also measured for on-body scenario with a male person, wearing thin t-shirt, by placing the antenna randomly on the belly and the comparison result was 


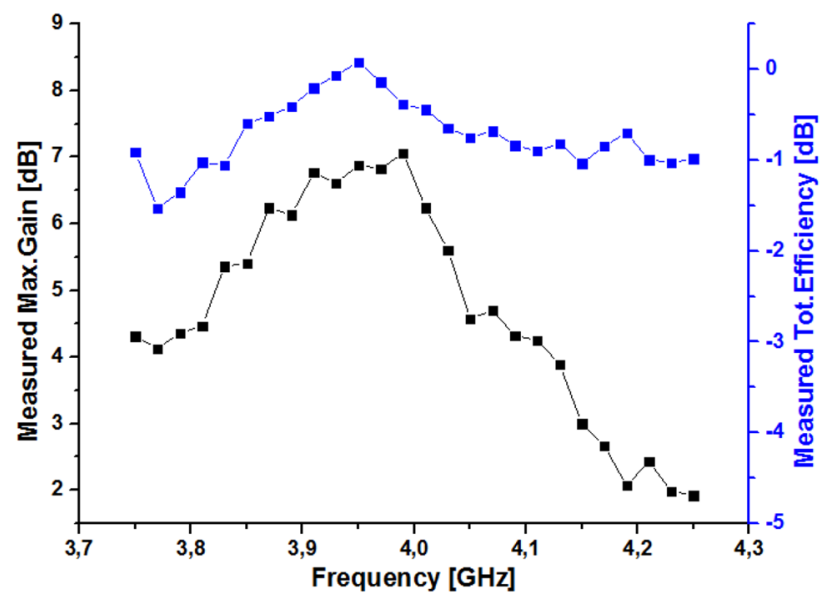

Fig. 10 Measured maximum gain and efficiency of the UWB cavitybacked antenna

provided in Fig. 9. The resulting bandwidth was widened $3.32-4.86 \mathrm{GHz}$, while the resonant frequency was quite the same. According to Fig. 10, the cavity-backed antenna performs to radiate well and has a good measured gain of $7 \mathrm{dBi}$ at $4 \mathrm{GHz}$. Back to related works, few researches were addressed to localize the capsule endoscope antenna in low-UWB band. In [15-18] the receiving antennas used in investigations are standard ones commonly used in diverse on- and off-body communications. Their limitations remain basically in low gain compared with the proposed cavitybacked antenna.

The measured radiation pattern of the cavity-backed antenna was compared to the simulated one as depicted in Fig. 11. Table 2 groups the comparison of the reported measured and simulated gain at $3.75 \mathrm{GHz}, 4.00 \mathrm{GHz}$ and 4.25 GHz, according to $\mathrm{Phi}=0^{\circ}, \mathrm{Phi}=90^{\circ}$ and Theta $=90^{\circ}$ cuts. The simulated and measured results are in good agreement, showing the maximum gain at $\mathrm{Phi}=90^{\circ}$ of $7.70 \mathrm{dBi}$, $8.00 \mathrm{dBi}$ and $5.05 \mathrm{dBi}$ against $7.17 \mathrm{dBi}, 7.00 \mathrm{dBi}$ and $7.12 \mathrm{dBi}$ at $3.75 \mathrm{GHz}, 4.00 \mathrm{GHz}$ and $4.25 \mathrm{GHz}$, respectively. The slight difference in radiation pattern shape is justified by the current overflow over the coaxial cable due to the fact that the antenna is a balanced structure and the coaxial cable is unbalanced.

\section{On-body Study}

A detailed on-body study is presented in this section. Simulated and measured results are compared and discussed.

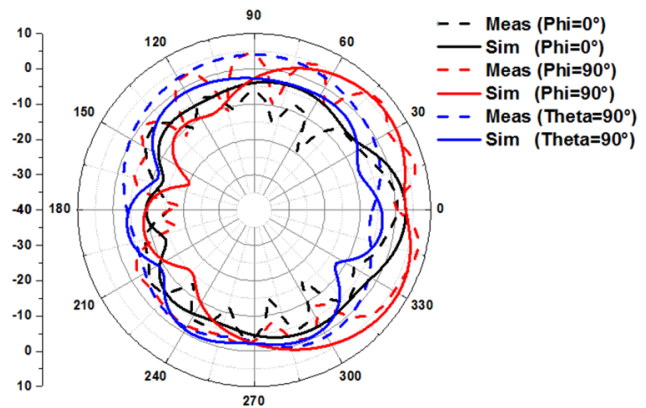

(a)

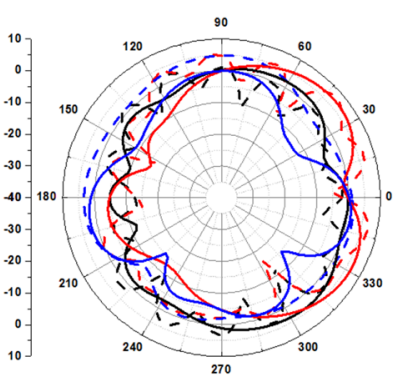

(b)

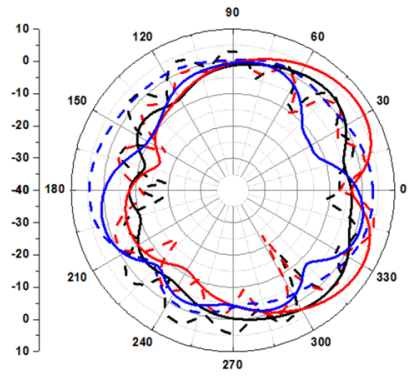

(c)
Fig. 11 Simulated and measured radiation pattern comparison in $\mathrm{dB}$ of UWB cavity-backed antenna at a 3.75 b 4.00 and c $4.25 \mathrm{GHz}$

\subsection{Simulation Results}

To simulate the on-body use of the proposed cavity-backed antenna, a multi-layer model was used to emulate the human body (Small Intestine area). The multi-layer model is based on 6 layers, which are skin, fat1, muscle, fat2, SI wall, SI content, with the features [19-22] are described in Table 3. By assuming the visceral fat (Fat2 layer) the most influencing component in the abdomen area for different persons, two different thicknesses were considered of $25 \mathrm{~mm}$ and $73 \mathrm{~mm}$ for "Thin" and "Fat" person case. The thickness of the remaining layers was fixed to $1.4 \mathrm{~mm}, 25 \mathrm{~mm}, 12 \mathrm{~mm}$, $1 \mathrm{~mm}$ and $20 \mathrm{~mm}$ for Skin, Fat1, Muscle, SI Wall and SI Content, respectively. The size totaling the multi-layer is $220 \mathrm{~mm}$ length, $220 \mathrm{~mm}$ width, and $87 \mathrm{~mm}$ height. This sub-section investigates the cavity-backed antenna performances in close proximity to human body. The antenna separation distance $d$ is defined as the distance between the cavity edge and the skin surface as illustrated in Fig. 12a, which is easy to reproduce accuratly in measurements. The $30 \mathrm{~mm}$ distance roughly corresponds to half near field region of the studied antenna. Next, Laura voxel model was used to approach the realistic measurement application. As depicted in Fig. 12b, c, the antenna performances were assessed on the "Navel" and "Back" sides with the closest separation distance from the skin layer, roughly estimated $2 \mathrm{~mm}$ and $4 \mathrm{~mm}$, respectively, because of the body shape. The boundary conditions were fixed in such way to enclose the model 
Table 2 Simulated and measured gains of uwb cavity-backed antenna per cut plans

Simulated Max Tot.Gain [dB]

\begin{tabular}{lllc}
\hline $\mathrm{F}[\mathrm{GHz}]$ & $\mathrm{Phi}=0^{\circ}$ & $\mathrm{Phi}=90^{\circ}$ & Theta $=90^{\circ}$ \\
\hline 3.75 & 2.95 & 7.17 & -0.538 \\
4 & 3.69 & 6.99 & 2 \\
4.25 & 3.16 & 7.12 & 1.4 \\
\hline
\end{tabular}

Measured Max Tot. Gain [dB]

\begin{tabular}{llll}
\hline $\mathrm{F}[\mathrm{GHz}]$ & $\mathrm{Phi}=0^{\circ}$ & $\mathrm{Phi}=90^{\circ}$ & Theta $=90^{\circ}$ \\
\hline 3.75 & 0.69 & 7.70 & 4.01 \\
4 & 3.63 & 7.99 & 4.77 \\
4.25 & 4.54 & 5.05 & 4.44 \\
\hline
\end{tabular}

Table 3 Tissue layer details at $4 \mathrm{GHz}$

\begin{tabular}{llllll}
\hline Tissue Layers & Skin & Fat & Muscle & SI wall & SI content \\
\hline Permittivity & 40.85 & 5.125 & 50.82 & 50.82 & 51.63 \\
$\begin{array}{l}\text { Conductivity } \\
(\mathrm{S} / \mathrm{m})\end{array}$ & 2.701 & 0.1829 & 3.015 & 3.015 & 4.622 \\
Density $\left(\mathrm{kg} / \mathrm{m}^{3}\right)$ & 1100 & 910 & 1041 & 1020 & 1020 \\
\hline
\end{tabular}

cut, as shown in Fig. 12b, so as to avoid any power overflow. Figure 12c provides an insight of the inner body tissues according to X-cut section. It is important to evaluate the antenna interaction with different parts of the body because the antenna will serve of a monitoring device held on the patient and handled by the medical doctor. Besides, with the extension and the meandered-shape of the SI tract, it is necessary to analyze the antenna behavior with different body parts.

In the following investigations, the cavity-backed antenna model corresponding to the antenna prototype is considered. The antenna has a $-10 \mathrm{~dB}$ bandwidth of $3.92-4.62 \mathrm{GHz}$ and 3.59-4.45 GHz, in both thin and fat study cases, for $d=4 \mathrm{~mm}$ and $d=30 \mathrm{~mm}$, respectively, as shown in Fig. 13a. It can be concluded that the human tissue thicknesses do not affect the antenna performance in terms of matching, whereas the separation distance $d$ does. By comparing the on-body measured case in Fig. 9 with the simulated ones for $d=4 \mathrm{~mm}$ presented in Fig. 13a, little divergence is remarked because it is challenging to manually design a realistic model. Moreover, the reflection coefficient of the antenna using voxel model is plotted in Fig. 13b for navel and back cases as known under "Navel_Voxel" and "Back_Voxel" names, respectively. Results show that the upper frequency is constant of $4.45 \mathrm{GHz}$ while the lower frequency knew a slight increase from 3.68 to $3.74 \mathrm{GHz}$ for "Back_Voxel" case. Interestingly, this time the on-body measured reflection coefficient matches closer the "Navel_Voxel" result.
The power pattern flows of the cavity-backed model for thin and fat persons with $4 \mathrm{~mm}$ and $30 \mathrm{~mm}$ separation distance using multilayer and voxel models can be found in [23, 24]. It is clearly vizualized how the SI layer is reached even for fat person study case. For thin person, the power pattern not only reach the SI wall but it exceeds it to cover the SI content as well. These investigation results promote the cavity-backed antenna use for wireless capsule endoscopy localization.

3D directivity results for the ofermentioned study cases using multilayer and voxel models are illustrated in Fig. 14. Maximum directivity (Max D) values are reported in Table 4 . The antenna gain is averaging $-5 \mathrm{~dB}$ at $4 \mathrm{~mm}$ and $30 \mathrm{~mm}$ distance from the multi-layer model. When using voxel model, a relatively raised gain of $0 \mathrm{~dB}$ and $2.51 \mathrm{~dB}$ was noticed on "Navel" and "Back" cases, respectively. This results strongly depends on the reported total efficiency values which enhance with the antenna-skin distance increase as presented in Table 4. Furthermore, the antenna matching in terms of input impedance of the UWB cavity-backed antenna is assessed as well. The investigation results are grouped in the same table showing that the antenna has a capacitive behavior for $d=4 \mathrm{~mm}$, while an inductive behavior is revealed for $d=30 \mathrm{~mm}$. According to the same table, it is noticed that when placing the antenna so close to the voxel model, the antenna has an inductive behavior. On the Navel, the resistance is about $45 \Omega$ compared to $29.3 \Omega$ on the back, which is caused by the different nature, in terms of the dielectric properties, of the surrounding realistic human tissues. Besides that, the antenna resistance remains quite constant averaging $54 \Omega$ for $d=4 \mathrm{~mm}$, while this parameter is increased about $60 \Omega$ for $d=30 \mathrm{~mm}$.

A detailed simulated and measurement study providing the free-space propagation, using the proposed cavitybacked antenna, was presented in [25]. Moreover, the channel propagation using the proposed cavity-backed antenna 


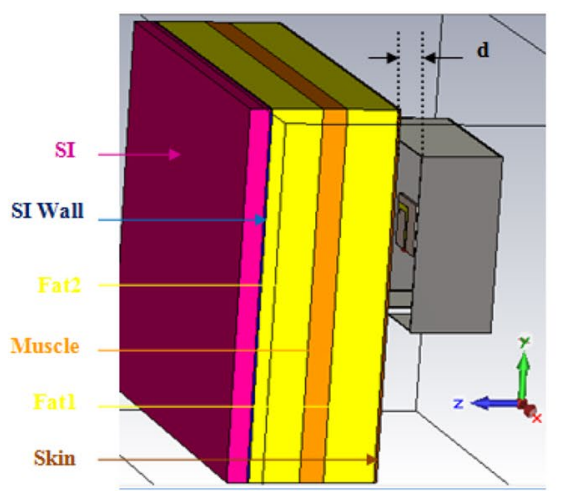

(a)

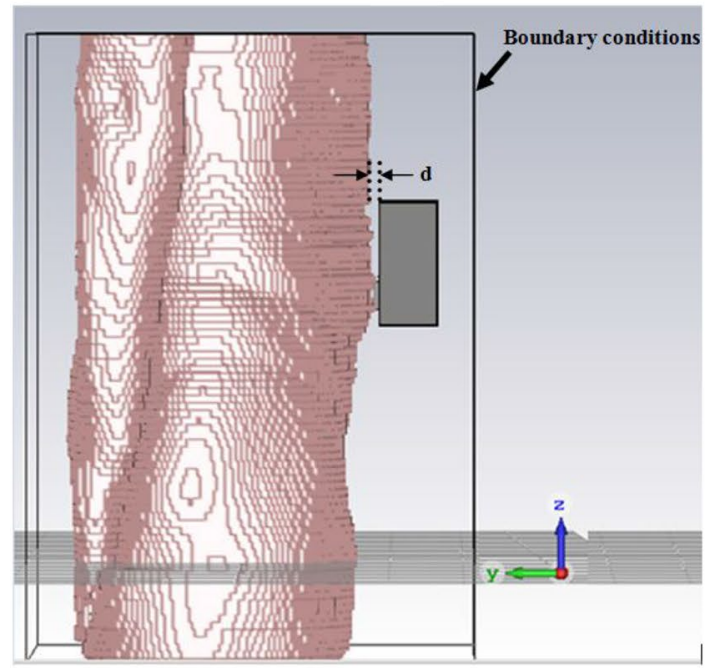

(b)

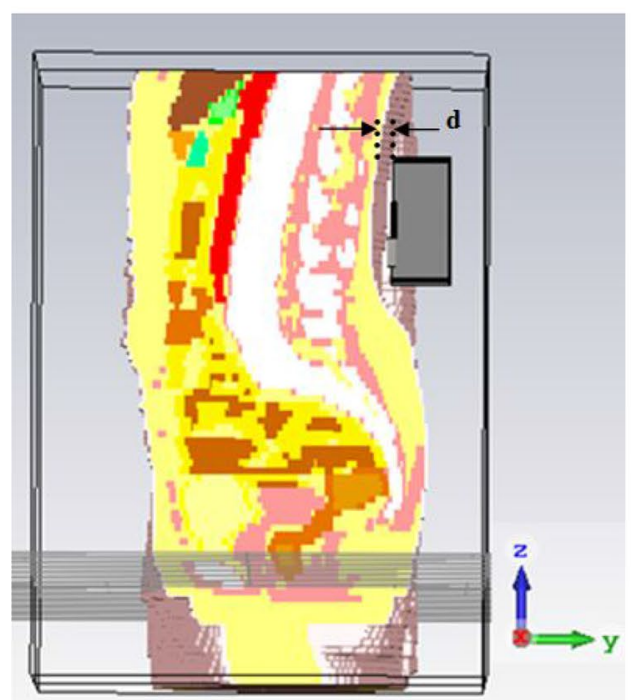

(c)

Fig. 12 UWB cavity-backed antenna in close proximity to human model using a multi-layer model and b "Navel" and c "Back" sides of voxel model

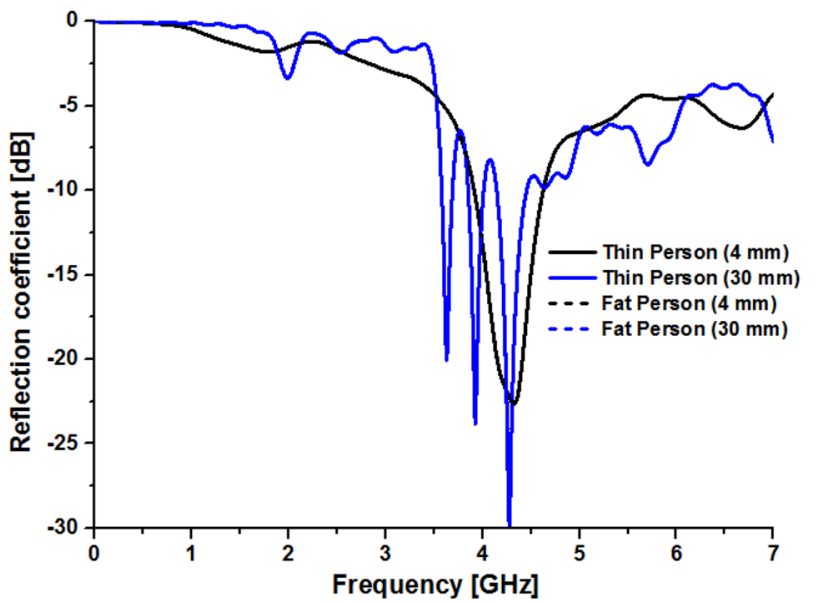

(a)

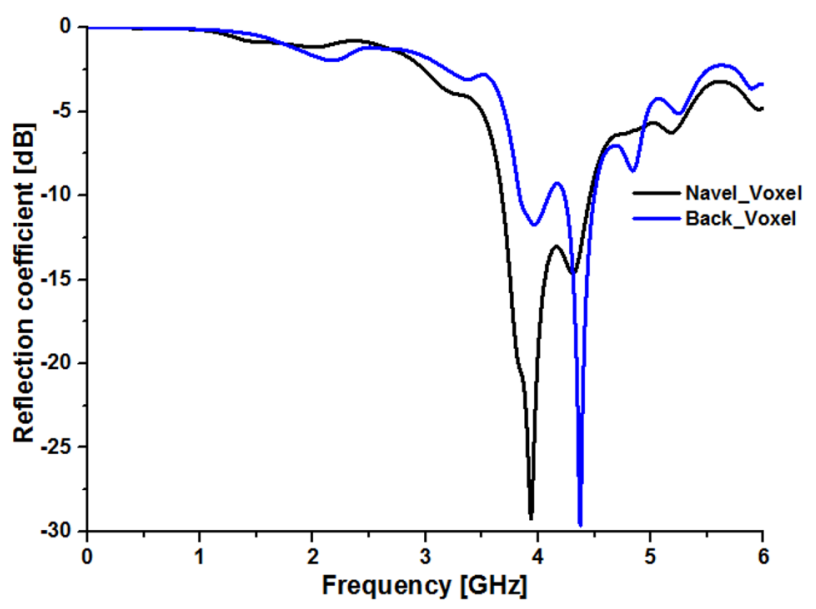

(b)

Fig. 13 Simulated reflection coefficient of UWB cavity-backed antenna in close proximity to a multi-layer and $\mathbf{b}$ voxel models

was discussed on multi-layer and voxel models, in time and frequency domains in [24] and results were confirmed by measurements for male and female cases. Furthermore, the effect of the distance separating the cavity-backed antenna from body surface was assessed and analyzed in [26]. In this context, in literature, few researches were conducted to investigate the antenna performances in close proximity to lossy tissues [27-29].

The antenna safety is a primordial element to be controlled before starting measurements on real persons. This is evaluated by the Specific Absorption Rate (SAR) and compared to normalized safety guidelines. In this paper, the SAR calculations were made by means of CST calculations on a multi-layer model emulating "Normal" person case. The SAR estimations were in compliance with IEEE/ IEC 62704-1 on $1 \mathrm{~g}$ tissue average. Both $d$ distances of $4 \mathrm{~mm}$ 


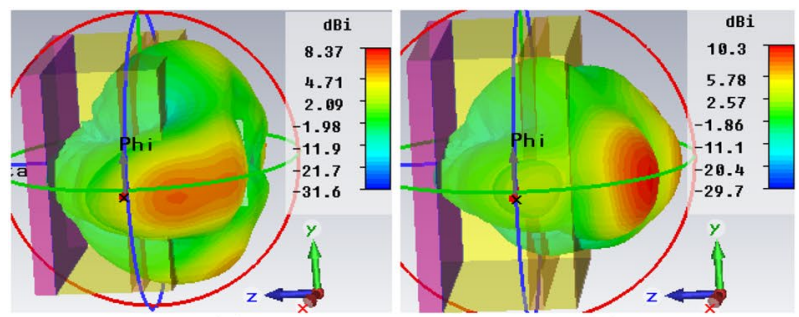

(a)

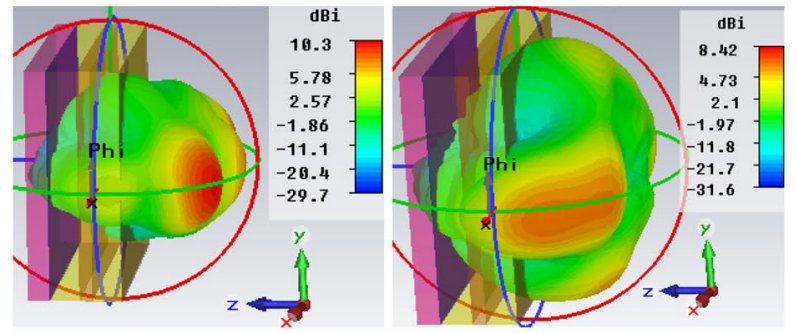

(c)

(d)

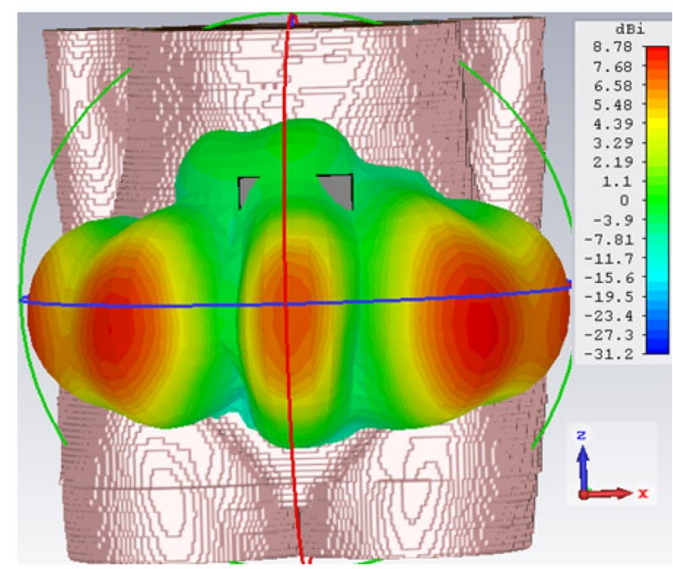

(e)

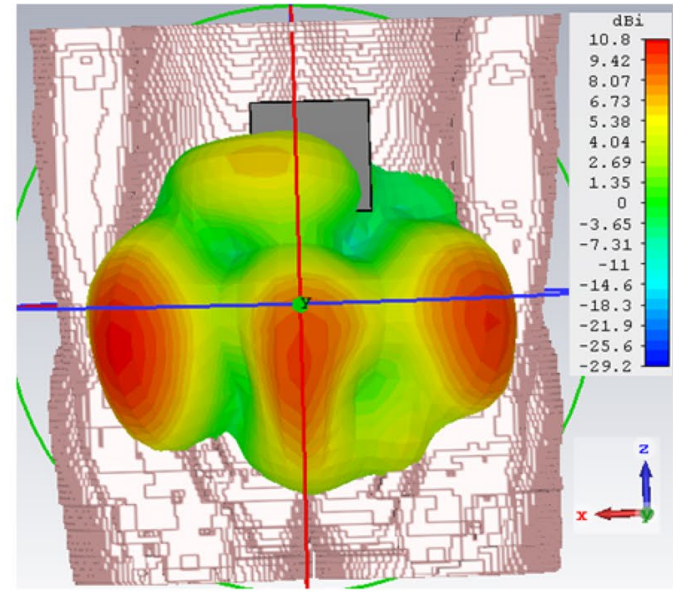

(f)

Fig. 14 3D directivity at $4 \mathrm{GHz}$ of the UWB cavity-backed antenna in close proximity to human tissues for a Fat person $\mathrm{d}=30 \mathrm{~mm}, \mathbf{b}$ Fat person $\mathrm{d}=4 \mathrm{~mm}, \mathbf{c}$ Thin person $\mathrm{d}=4 \mathrm{~mm}, \mathbf{d}$ thin person $\mathrm{d}=30 \mathrm{~mm}, \mathbf{e}$ Navel_Voxel and $\mathbf{f}$ Back_Voxel
Table 4 The antenna features of the cavity-backed antenna at $4 \mathrm{GHz}$ using multi-layer and voxel models

\begin{tabular}{lllll}
\hline Study case & $\begin{array}{l}\text { Input impedance } \\
{[\Omega]}\end{array}$ & $\begin{array}{l}\text { Max D } \\
{[\mathrm{dBi}]}\end{array}$ & $\begin{array}{l}\text { Tot Eff } \\
{[\mathrm{dB}]}\end{array}$ & $\begin{array}{l}\text { Gain } \\
{[\mathrm{dB}]}\end{array}$ \\
\hline $\begin{array}{c}\text { Thin person } \\
(\mathrm{d}=4 \mathrm{~mm})\end{array}$ & $53.48-\mathrm{j} 21.19$ & 10.30 & -14.53 & -4.26 \\
$\begin{array}{c}\text { Fat person } \\
(\mathrm{d}=4 \mathrm{~mm})\end{array}$ & $54.15-\mathrm{j} 22.08$ & 10.30 & -14.54 & -4.26 \\
$\begin{array}{l}\text { Fat person } \\
(\mathrm{d}=30 \mathrm{~mm})\end{array}$ & $59.69+\mathrm{j} 30.50$ & 8.37 & -2.95 & -5.41 \\
$\begin{array}{c}\text { Thin person } \\
(\mathrm{d}=30 \mathrm{~mm})\end{array}$ & $62.32+\mathrm{j} 32.49$ & 8.42 & -2.95 & -5.47 \\
$\begin{array}{l}\text { Navel_Voxel } \\
\text { Back_Voxel }\end{array}$ & $44.99+\mathrm{j} 10.15$ & 8.78 & -8.73 & 0.05 \\
\hline
\end{tabular}

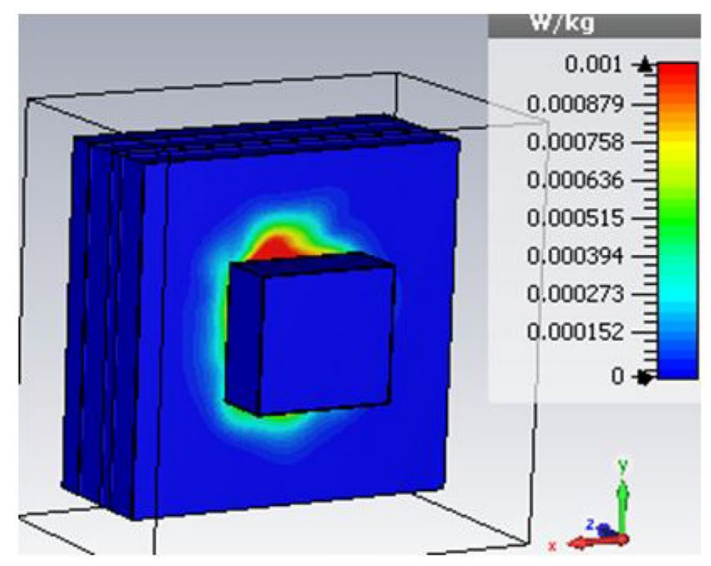

(a)

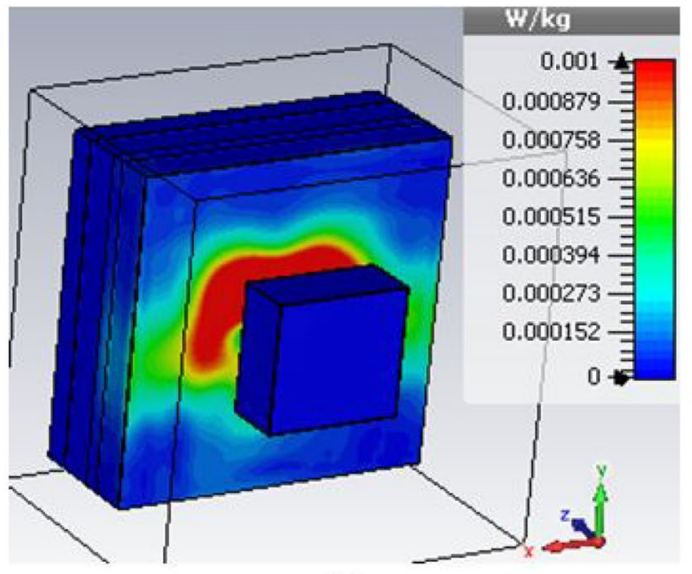

(b)

Fig. 15 SAR results on $1 \mathrm{~g}$ average tissue according to IEEE/ IEC62704-1 for $\mathbf{a} d=4 \mathrm{~mm}$ and $\mathbf{b} d=30 \mathrm{~mm}$ 
and $30 \mathrm{~mm}$ were considered as illustrated in Fig. 15, revealing maximum SAR values of $0.112 \mathrm{~W} / \mathrm{kg}$ and $0.005 \mathrm{~W} / \mathrm{kg}$, respectively. These results validate the antenna safety on the human body.

\subsection{Measurement Results}

This section deals with the measured results of the cavitybacked antenna in on-body scenarios. The measurements were conducted in an anechoic chamber at Oulu University, Finland. The SAR limit value of the proposed antenna was estimated by CST calculations using multi-layer, and the latest male and female voxel models in [24, 25], to meet the safety guidelines. The antenna matching was assessed by holding the antenna by two females at different body part positions for the "abdomen" scenario. The antennas were attached to the human subjects by elastic bands. The female subjects were wearing thin clothes, as depicted in Fig. 16, to minimize additional clothes effects. Different on-body "Abdomen" antenna positions are defined and presented in

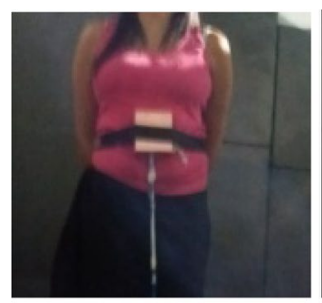

(a)

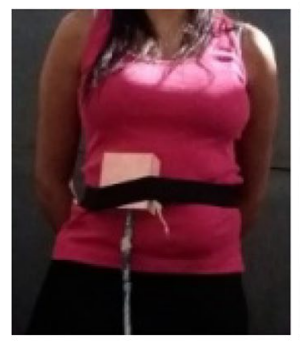

(d)

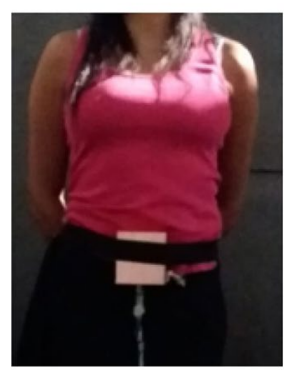

(g)

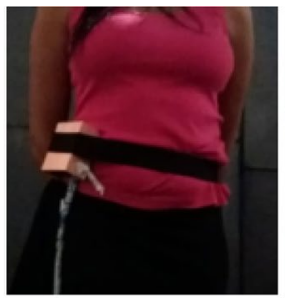

(b)

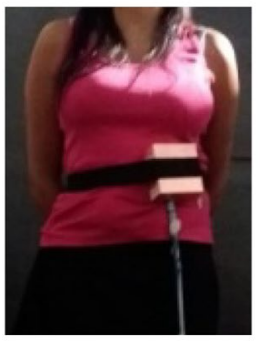

(e)

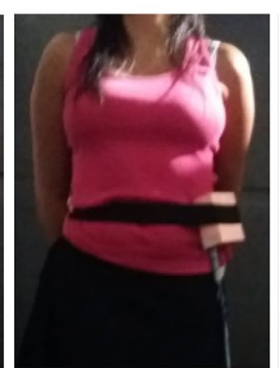

(h)

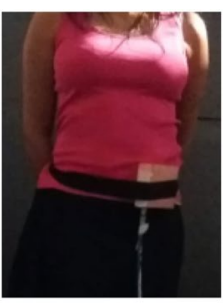

(c)

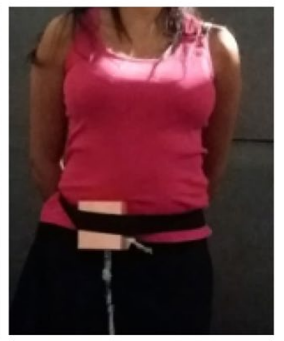

(f)

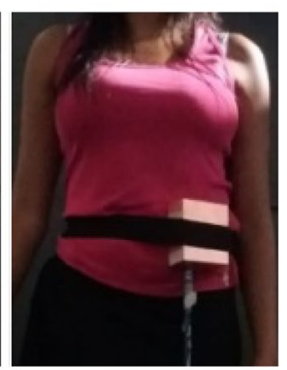

(i)
Fig. 16 Different antenna positions of the UWB cavity-backed antenna for "Abdomen" scenario. a Navel, b flank right, c down left, d position E, e up left, $\mathbf{f}$ down right, $\mathbf{g}$ down navel, $\mathbf{h}$ flank left, $\mathbf{i}$ position B

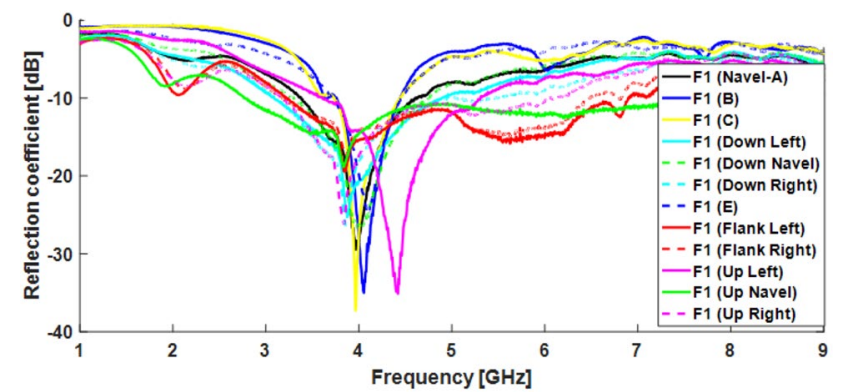

(a)

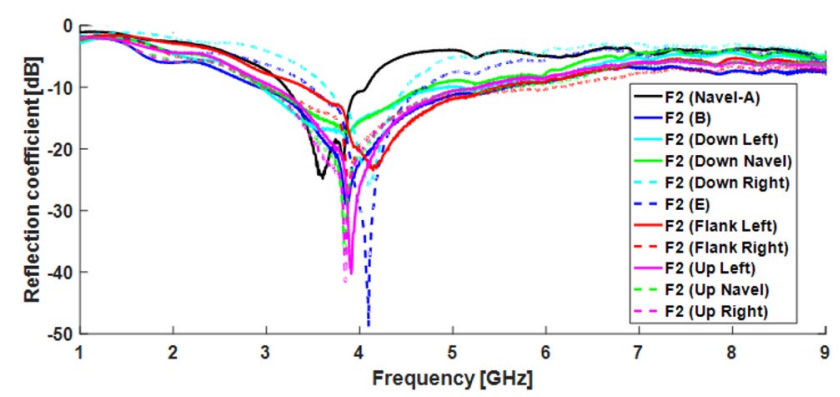

(b)

Fig. 17 Measured reflection coefficient of the Low-UWB cavitybacked antenna for "Abdomen" scenario on two females a F1 and b F2

Table 5 Measured reflection coefficient of the cavity-backed antenna for on-body "abdomen" scenario

\begin{tabular}{llll}
\hline Abdomen position & $\begin{array}{l}\text { Fr [GHz] } \\
\text { (F1/F2) }\end{array}$ & $\begin{array}{l}\text { Max.S11 [dB] } \\
\text { (F1/F2) }\end{array}$ & $\begin{array}{l}\text { Bandwidth [GHz] } \\
\text { (F1/F2) }\end{array}$ \\
\hline Navel (A) & $3.97 / 3.6$ & $-29.46 /-24.82$ & $\begin{array}{l}3.39-4.6 / 3.20-4.07 \\
\text { B }\end{array}$ \\
& $4.05 / 3.86$ & $-34.99 /-29.06$ & $\begin{array}{l}3.77-4.43 / 2.95- \\
5.63\end{array}$ \\
Down left & $3.88 / 3.89$ & $-26.55 /-18.29$ & $3.13-5.09 / 2.94-$ \\
& & & 4.85 \\
Down navel & $4.02 / 3.89$ & $-26.32 /-17.34$ & $3.30-4.74 / 3.01-$ \\
& & & 4.72 \\
Down right & $3.84 / 4.10$ & $-26.46 /-26.14$ & $3.14-4.75 / 3.65-$ \\
& & & 4.49 \\
E & $4.12 / 4.10$ & $-24.63 /-48.92$ & $3.73-4.45 / 3.50-$ \\
& & & 4.69 \\
Flank left & $3.84 / 4.14$ & $-19.37 /-23.49$ & $3.26-6.68 / 3.41-$ \\
& & & 5.49 \\
Flank right & $3.87 / 3.88$ & $-17.09 /-26.49$ & $3.21-6.53 / 2.96-$ \\
& & & 6.03 \\
Up left & $4.42 / 3.91$ & $-35.10 /-40.24$ & $3.62-5.31 / 3.08-$ \\
& & & 5.30 \\
Up navel & $3.85 / 3.84$ & $-18.35 /-37.01$ & $2.76-4.85 / 2.95-$ \\
& & & 5.55 \\
Up right & $3.84 / 3.84$ & $-26.19 /-41.53$ & $3.17-4.88 / 3.01-$ \\
& & & 5.35 \\
\hline & & &
\end{tabular}




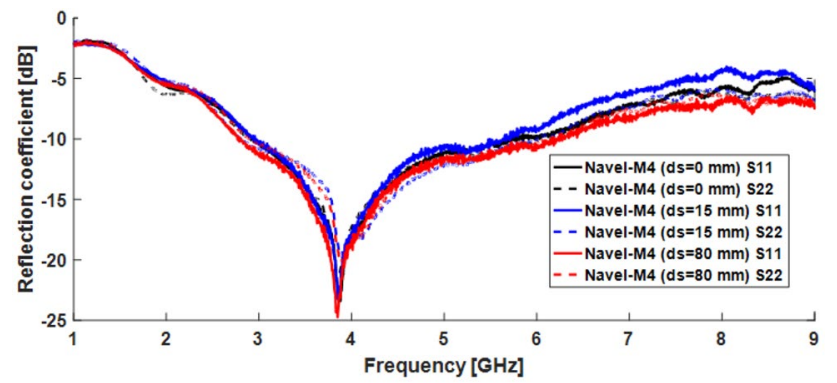

(a)

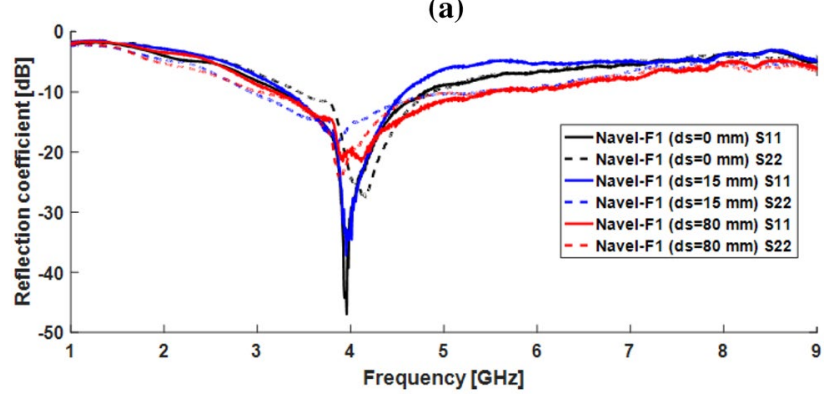

(b)

Fig. 18 Measured reflection coefficient of the Low-UWB cavitybacked antenna for "Navel" scenario on a Male 'M4' and b Female 'F1'

real cases in Fig. 16. Since the SI tract has a curled shape, the aim of the different antenna positions is to circumvent as much as possible the abdomen area, where the SI tract could be present. This way, one can be certain regarding the good antenna matching at any chosen point of the abdomen body area.

The measured reflection coefficient results for on-body scenarios according to the antenna positions described in Fig. 16 for both female volunteers are presented in Fig. 17a, b. The measured reflection coefficient values are grouped in Table 5. It is validated that the 3.75-4.25 GHz bandwidth is covered for all the positions of the "Abdomen" area, this proves a well antenna matching in vicinity to the human body.

Next, the antenna matching experiment was focused on comparing the matching of the belly area with back area on real candidates to validate the results presented in previous section, these scenarios were known under the names "Navel" and "Back" thereafter. Measurements were conducted on a male (M4) and female (F1) and their informations are detailed in [25]. The channel propagation using two antennas on "Navel" and "Back" scenarios was investigated exhaustively as can be found in [30]. However, this paper will be restricted to show and discuss S11 and S22 results. Note that $d s$ is the distance between the cavity edges which is assumed $0 \mathrm{~mm}$ when the antennas are in contact. For all the scenarios the antennas are symmetrical
Table 6 Measured reflection coefficient of the cavity-backed antenna for on-body "navel" scenario

\begin{tabular}{llll}
\hline $\begin{array}{l}\text { Navel_position } \\
\text { (F1) }\end{array}$ & $\begin{array}{l}\text { Fr }[\mathrm{GHz}] \\
(\mathrm{S} 11 / \mathrm{S} 22)\end{array}$ & $\begin{array}{l}\text { Max.S11 [dB] } \\
(\mathrm{S} 11 / \mathrm{S} 22)\end{array}$ & $\begin{array}{l}\text { Bandwidth }[\mathrm{GHz}] \\
(\mathrm{S} 11 / \mathrm{S} 22)\end{array}$ \\
\hline$d s=0 \mathrm{~mm}$ & $3.96 / 4.10$ & $-46.96 /-27.52$ & $3.18-4.80 / 3.24-4.80$ \\
$d s=50 \mathrm{~mm}$ & $3.95 / 3.98$ & $-37.19 /-21.01$ & $3.18-4.55 / 3.24-4.80$ \\
$d s=80 \mathrm{~mm}$ & $4.13 / 3.90$ & $-21.12 /-24.04$ & $3.18-4.55 / 3.18-4.80$ \\
\hline
\end{tabular}

Table 7 Measured reflection coefficient of the cavity-backed antenna for on-body "back" scenario on 'F1'

\begin{tabular}{llll}
\hline $\begin{array}{l}\text { Back_position } \\
(\mathrm{F} 1)\end{array}$ & $\begin{array}{l}\text { Fr [GHz] } \\
(\mathrm{S} 11 / \mathrm{S} 22)\end{array}$ & $\begin{array}{l}\text { Max.S11 [dB] } \\
(\mathrm{S} 11 / \mathrm{S} 22)\end{array}$ & $\begin{array}{l}\text { Bandwidth }[\mathrm{GHz}] \\
(\mathrm{S} 11 / \mathrm{S} 22)\end{array}$ \\
\hline$d s=0 \mathrm{~mm}$ & $3.89 / 3.75$ & $-15.07 /-13.91$ & $3.71-4.06 / 3.53-4.02$ \\
$d s=50 \mathrm{~mm}$ & $3.99 / 3.86$ & $-47.03 /-35.97$ & $3.50-4.51 / 3.39-4.26$ \\
$d s=80 \mathrm{~mm}$ & $3.97 / 3.80$ & $-39.63 /-22.44$ & $3.56-4.43 / 3.15-4.43$ \\
\hline
\end{tabular}

Table 8 Measured reflection coefficient of the cavity-backed antenna for on-body "back" scenario on 'M4'

\begin{tabular}{llll}
\hline $\begin{array}{l}\text { Back_position } \\
(\mathrm{F} 1)\end{array}$ & $\begin{array}{l}\text { Fr [GHz] } \\
(\mathrm{S} 11 / \mathrm{S} 22)\end{array}$ & $\begin{array}{l}\text { Max.S11 [dB] } \\
(\mathrm{S} 11 / \mathrm{S} 22)\end{array}$ & $\begin{array}{l}\text { Bandwidth }[\mathrm{GHz}] \\
(\mathrm{S} 11 / \mathrm{S} 22)\end{array}$ \\
\hline$d s=0 \mathrm{~mm}$ & $4.01 / 4.01$ & $-21.47 /-34.00$ & $3.47-4.47 / 3.47-4.47$ \\
$d s=30 \mathrm{~mm}$ & $4.01 / 4.01$ & $-34.00 /-34.00$ & $3.47-4.47 / 3.47-4.47$ \\
$d s=50 \mathrm{~mm}$ & $4.01 / 3.96$ & $-34.00 /-12.61$ & $3.47-4.47 / 3.74-4.25$ \\
$d s=80 \mathrm{~mm}$ & $4.01 / 4.01$ & $-49.62 /-34.00$ & $2.78-6.1 / 3.47-4.47$ \\
\hline
\end{tabular}

to the navel. Similarly, for the "Back" scenario the antennas were maintained, to some extent, in the same navel level. Figure 18a, b show the reflection coefficient result according to "Navel" scenario for M4 and F1 with different distances $d s$, respectively. It is concluded that the resonant frequency at $3.85 \mathrm{GHz}$ with $-24 \mathrm{~dB}$ return loss and bandwidth $(\mathrm{S} 11<10 \mathrm{~dB})$ of $2.84-5.6 \mathrm{GHz}$ is maintained for all distances $d s$ in the case of 'M4'. While for F1, the bandwidth is slighty affected by the distance $(d s)$ change, however the resonant frequency is almost $4 \mathrm{GHz}$ with a maximum return loss up to $-49 \mathrm{~dB}$ as summarized in Table 6 . When it comes to the "Back" scenario for the same candidate, the difference in antenna matching results started to be noticed with the distance $d s$ as plotted in Fig. 19 and grouped in Table 7. Similar behavior is seen from Table 8 on 'M4'. The measurement results conducted in this sub-section are in agreement with the simulated ones using voxel model in Fig. 13b in terms of the covered $4 \mathrm{GHz}$ center frequency of $500 \mathrm{MHz}$ bandwidth. All these findings drive to the conclusion promoting the validity of the antenna application for the regarded BAN application i.e. Wireless Capsule Endoscopy localization at 


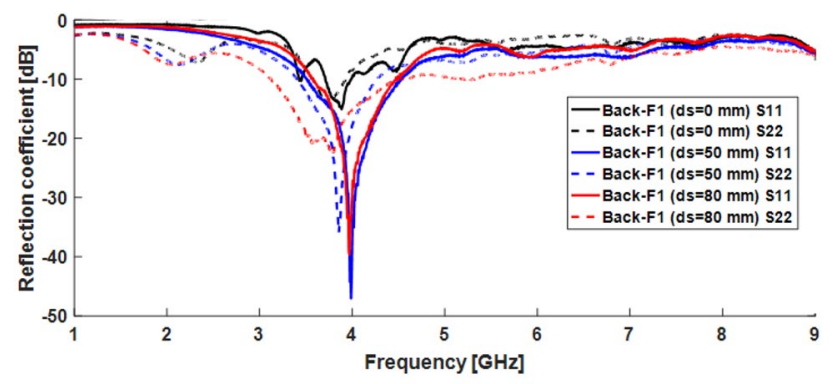

(a)

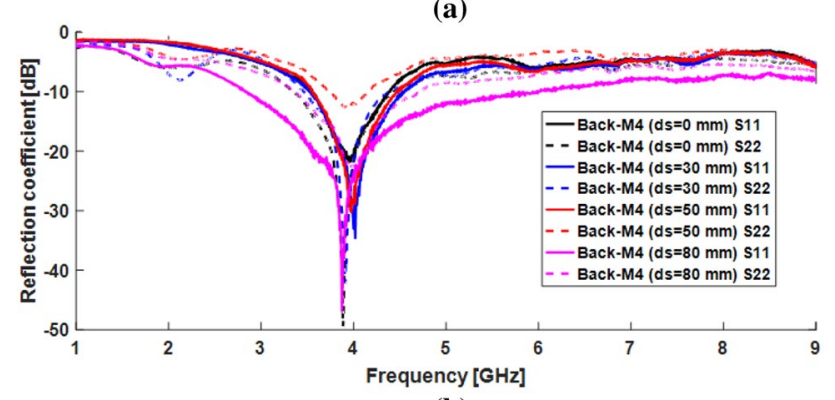

(b)

Fig. 19 Measured reflection coefficient of the Low-UWB cavitybacked antenna for "Back" scenario on a Female 'F1' and b Male 'M4'

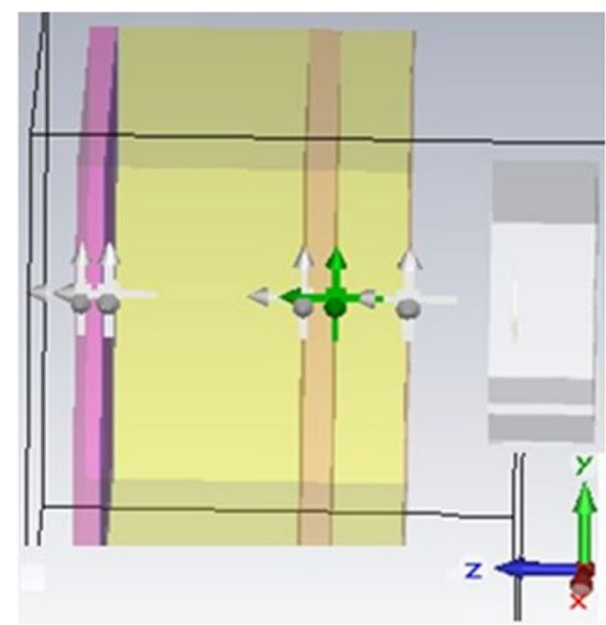

Fig. 20 Power-field probes emplacement inside the multi-layer model

Table 9 Power-field probe description using the multi-layer model

\begin{tabular}{ll}
\hline E-probe & Description \\
\hline Skin surface & Air-skin interface \\
Fat1 surface & Skin-fat1 interface \\
Muscle surface & Fat1-muscle interface \\
Fat2 surface & Muscle-fat2 interface \\
SI wall surface & Fat2-SI_wall interface \\
SI start surface & SI_wall-SI_content interface \\
SI middle surface & Middle of SI_content \\
SI end surface & SI_content-air interface \\
\hline
\end{tabular}

Low-UWB range, since the required $3.25-4.25 \mathrm{GHz}$ band is covered also in on-body use.

\section{In-body Study}

Power values using different probes were later calculated inside the multi-layer model, as described in Fig. 20. Table 9 describes the location of the power fields. The resulting values at $4 \mathrm{GHz}$ are summarized in Table 10 per study case. In CST simulations, the boundary conditions were set to "Open (Add space)" in all directions, in this paper, later different boundary conditions will be tested. For $d=4 \mathrm{~mm}$, the power-field probe results are decreasing in the following order: skin surface, fat 1 surface, muscle surface, fat 2 surface, SI wall surface, SI start surface, SI middle surface, and SI end surface at $4 \mathrm{GHz}$, for all the on-body cases as presented in Table 10. The power-field probes at skin, fat 1 and muscle and fat 2 surfaces reveal similar amount of power for thin and fat study cases when the antenna-skin separation distance is $4 \mathrm{~mm}$. Whereas a remarkable difference is seen at SI wall surface between the person study cases. To exemplify this, the power field is $-14.29 \mathrm{~dB}$ for thin person against $-23.10 \mathrm{~dB}$ for fat person explained by the higher thickness of the lossy tissue (fat). Then the power-fields continue decreasing by quite the same $\mathrm{dB}$ values for thin and fat person study cases. The captured power fields for both fat and thin persons at the skin surface is around $10.20 \mathrm{~dB}$ for $(d=30 \mathrm{~mm})$ compared with $28.44 \mathrm{~dB}$ for $(d=4 \mathrm{~mm})$. This is natural since the power-field arriving to the skin are deteriorated with distance increase. At $d=30 \mathrm{~mm}$, the same power absorption was observed within different layer tissues for thin and fat person cases. Consequenctly, it is reported from Table 8 that, the total power loss from skin to the end of SI layers is estimated $65.63 \mathrm{~dB}$ and $74.93 \mathrm{~dB}$ at $(d=4 \mathrm{~mm})$ for thin and fat person cases. The corresponding power values at $d=30 \mathrm{~mm}$ are decreased roughly by $9 \mathrm{~dB}$ for both cases. This slight difference can be related to the antenna radiation pattern shape and the gain. This aspect will still be investigated in coming papers using different antennas with different performances.

Next, the power absorption was estimated using voxel model from both "Navel" and "Back" sides. First, the antenna was situated in closest distance from the Navel of the voxel model, as figured in Fig. 21. Several power probes, counted to 5 , are placed between different tissues starting from skin to SI layers, as encircled in blue in Fig. 21. The localized/targeted points of interest are chosen: "just before skin" referring to the first probe before reaching skin tissue, "Skin" and "Fat" tissues are associated to probes within skin and fat tissues, and "Start and End of SI" correspond to the extreme parts faced in a line of sight direction. Details for surrounding tissues are mentioned as well in the same 
Table 10 Power-field probe results at $4 \mathrm{GHz}$ per study case using the multi-layer model

\begin{tabular}{lcccc}
\hline Power probes $[\mathrm{dB}]$ & $\begin{array}{l}\text { Thin person } \\
(d=4 \mathrm{~mm})\end{array}$ & $\begin{array}{l}\text { Fat person } \\
(d=4 \mathrm{~mm})\end{array}$ & $\begin{array}{c}\text { Thin person } \\
(d=30 \mathrm{~mm})\end{array}$ & $\begin{array}{c}\text { Fat person } \\
(d=30 \mathrm{~mm})\end{array}$ \\
\hline Skin surface & 28.43 & 28.44 & 10.23 & 10.20 \\
Fat1 surface & 26.18 & 26.18 & 8.47 & 8.43 \\
Muscle surface & 7.94 & 7.94 & -0.064 & -0.056 \\
Fat2 surface & -2.6 & -2.6 & -9.92 & -9.64 \\
SI wall surface & -14.29 & -23.10 & -19.06 & -29.87 \\
SI start surface & -15.11 & -24.08 & -19.95 & -30.48 \\
SI Middle surface & -26.02 & -36.01 & -31.44 & -40.46 \\
SI End surface & -37.20 & -46.49 & -41.21 & -50.75 \\
Skin-SI Total power & 65.63 & 74.93 & 51.43 & 60.95 \\
\hline
\end{tabular}

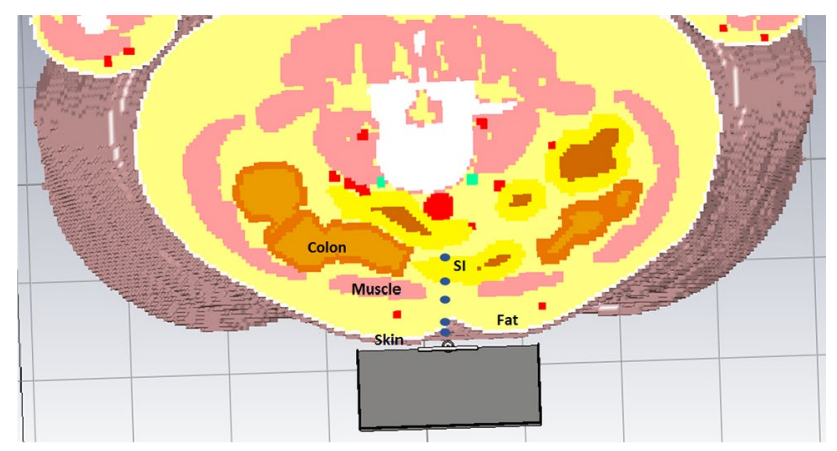

Fig. 21 Power-field probes emplacement inside the voxel model in "Navel" side

Table 11 Power-field probe results at $4 \mathrm{GHz}$ using voxel model

\begin{tabular}{llll}
\hline $\begin{array}{l}\text { Power probes } \\
{[\mathrm{dB}]}\end{array}$ & Navel_Voxel & $\begin{array}{l}\text { Power probes } \\
{[\mathrm{dB}]}\end{array}$ & Back_Voxel \\
\hline Just before skin & 0 & Just before skin & 0 \\
Skin tissue & -2 & Skin tissue & -2 \\
Fat tissue & -4 & Fat tissue & -4.8 \\
Start of SI tissue & -12 & Muscle tisue & -17 \\
End of SI tissue & -29 & Bone tissue & -71 \\
$\begin{array}{l}\text { Skin-SI Total } \\
\text { power }\end{array}$ & 29 & Start of SI tissue & -70 \\
& & End of SI tissue & -60 \\
& & Skin-SI Total & 60 \\
& & power & \\
\hline
\end{tabular}

figure. Initially, assuming the normalized power value of $0 \mathrm{~dB}$ "Just before skin", the power is decreased by $2 \mathrm{~dB}$ in skin and fat tissues, as grouped in Table 11. By arriving the SI layer, the power dropped to $-12 \mathrm{~dB}$. By travelling the SI layer, the power reached $-29 \mathrm{~dB}$. This power is less than the estimation provided using multi-layer model. This is evident

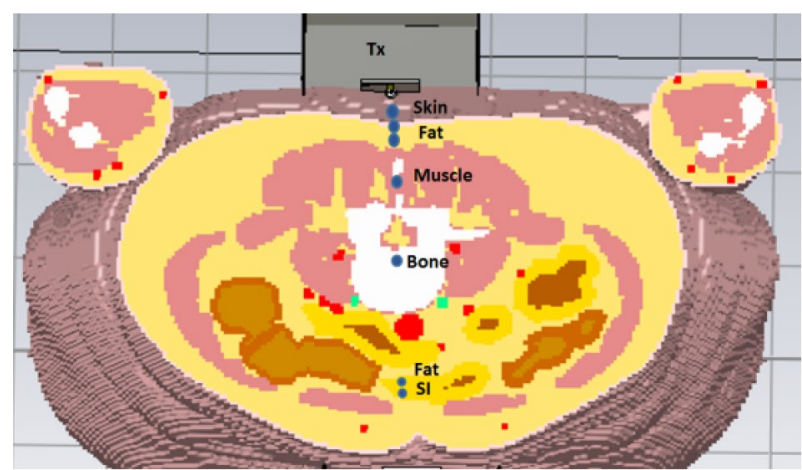

Fig. 22 Power-field probes emplacement inside the voxel model in "Back" side

since the signal would find different paths to propagate and will end by chosen the easiest using the realistic model. Later, the power values were calculated for "Back" side as illustrated in Fig. 22. This time, the probes were situated within a line starting from skin layer of the Voxel_back to the same SI segment as shown in Fig. 22. From Table 11, in skin layer the power is $-2 \mathrm{~dB}$ which is slightly decreased to $-4.8 \mathrm{~dB}$ in fat tissue. At muscle and bone tissues, the value becomes $-17 \mathrm{~dB}$ and $-71 \mathrm{~dB}$. This sharp decrease is caused by the challenging lossy tissues. At the start of SI, the power remained roughly the same about $-70 \mathrm{~dB}$ as at the bone tissue. This equal power level supports the idea that the signal arriving the SI has chosen a rapid path rather that passing by bone tissue. By arriving the end of SI layer, the power amount is estimated $60 \mathrm{~dB}$. Ref [31] delivers a detailed comprehensive analysis for signal propagation through fat layer. It is remarkable that the average power loss from skin to SI layer in "Navel" side is lower than in "Back" side, which is due to the high tissue layers i.e. Bone and muscle faced in "Back" side besides of being the most challenging tissues for channel propagation. Ref [30] discusses the communication link between the proposed antenna and a modelled capsule antenna by providing the best position to place the on-body antenna. 


\section{Conclusion and Perspectives}

The paper presents the improvement of an UWB cavity-backed antenna operating at low UWB band at 3.75-4.25 GHz, defined in IEEE 802.15.6 standard for WBAN applications. The antenna is firstly built in single structure, to which a cavity was later introduced with the aim to change the main radiation and increase the antenna gain. The cavity-backed structure was assessed in on-body scenarios using a multi-layer model emulating the SI body part and completed by voxel model investigations. Different person cases named "thin" and "fat" were considered, by taking into account an antenna-skin distance of $4 \mathrm{~mm}$ and $30 \mathrm{~mm}$. The proposed cavity-backed antenna was measured in free-space and in on-body wearable use.

The results show the suitability of the proposed cavitybacked antenna to wireless capsule endoscopy localization purposes. This is supported by the measured gain of $8 \mathrm{dBi}$ with good total efficiency. The antenna performances were investigated in details in terms of impedance matching, freespace and channel propagation by using multi-layer models and latest voxel models. The impact of the antenna-skin distance in time and frequency domain using two cavity-backed antennas was presented.

Acknowledgements Open access funding provided by University of Oulu including Oulu University Hospital. Authors would like to thank Professor Heli Jantunen and all in Microelectronics research unit team for the help on antenna design and measurements. This research has been financially supported in part by Academy of Finland 6GGenesis Flagship (Grant 318927).

Open Access This article is distributed under the terms of the Creative Commons Attribution 4.0 International License (http://creativeco mmons.org/licenses/by/4.0/), which permits unrestricted use, distribution, and reproduction in any medium, provided you give appropriate credit to the original author(s) and the source, provide a link to the Creative Commons license, and indicate if changes were made.

\section{References}

1. A. Alomainy, Y. Hao, D. M. Davenport, Parametric study of wearable antennas with varying distances from the body and different on-body positions, IET Seminar on Antennas and Propagation for Body-Centric Wireless Communications, pp. 84-89, 2007.

2. S. Seneviratne, Y. Hu, T. Nguyen, G. Lan, S. Khalifa, K. Thilakarathna, M. Hassan and A. Seneviratne, A survey of wearable devices and challenges, IEEE Communications Surveys \& Tutorials, Vol. 19, pp. 2573-2620, 2017.

3. S. Seneviratne, Y. Hu, T. Nguyen, G. Lan, S. Khalifa, K. Thilakarathna, M. Hassan and A. Seneviratne, A comprehensive survey of wireless body area networks, IEEE Communications Surveys \& Tutorials, Vol. 19, No. 4, pp. 2573-2620, 2017.

4. N. Kalid, A. A. Zaidan, B. B. Zaidan, O. H. Salman, M. Hashim and $\mathrm{H}$. Muzammil, Based real time remote health monitoring systems: a review on patients prioritization and related "Big Data" using body sensors information and communication technology, Journal of Medical Systems, Vol. 42, pp. 1-30, 2018.

5. Q. H. Abbasi, M. U. Rehman, K. Qaraqe and A. Alomainy, Advances in Body-Centric Wireless Communication: Applications and State-of-the-art, Institution of Engineering and TechnologyStevenage, 2016.

6. K. M. S. Thotahewa, J. M. Redoutè and M. R. Yuce, Propagation, power absorption, and temperature analysis of UWB wireless capsule endoscopy devices operating in the human body, IEEE Transactions on Microwave Theory and Techniques, Vol. 63, pp. 3823-3833, 2015.

7. U. Khan, Y. Ye, A. U. Aisha, P. Swar and K. Pahlavan, Precision of EM simulation based wireless location estimation in multisensor capsule endoscopy, IEEE Journal of Translational Engineering in Health and Medicine, Vol. 6, p. 1, 2018.

8. G. Bao, K. Pahlavan and L. Mi, Hybrid localization of microrobotic endoscopic capsule inside small intestine by data fusion of vision and RF sensors, IEEE Sensors Journal, Vol. 15, No. 5, pp. 2669-2678, 2015.

9. R. Chandra, A. J. Johansson, M. Gustafsson and F. Tufvesson, A microwave imaging based technique to localize an in-body RFsource for biomedical applications, IEEE Transactions on Biomedical Engineering, Vol. 62, No. 5, pp. 1231-1241, 2015.

10. D. Yang, J. Hu and S. Liu, A low profile UWB antenna for WBAN applications, IEEE Access, Vol. 6, pp. 25214-25219, 2018.

11. T. S. P. See, T. M. Chiam, M. C. K. Ho and M. R. Yuce, Experimental study on the dependence of antenna type and polarization on the link reliability in on-body UWB systems, IEEE Transactions on Antennas and Propagation, Vol. 60, pp. 5373-5380, 2012.

12. H. Liu, J. Sarrazin, F. Deshours, T. Mavridis, L. Petrillo, Z. Liu, P. D. Doncker and A. B.- Delaï, Performance assessment of IRUWB body area network (BAN) based on IEEE 802.15.6 standard, IEEE Antennas and Wireless Propagation Letters, Vol. 15, pp. 1645-1648, 2016.

13. IEEE Standard for Local and metropolitan area networks _Part 15.6: Wireless Body Area Networks, pp. IEEE Std 802.15.6-2012, pp. 1-271, 2012.

14. C. Kissi, M. Särestöniemi, C. P. Raez, M. Sonkki, and M. N. Srifi, Low-UWB directive antenna for Wireless Capsule Endoscopy localization", presented in BodyNets 2018 conference, Oulu, Finland, October 2018.

15. Q. Wang, K. Wolf, and D. Plettemeier, An uwb capsule endoscope antenna design for biomedical communications, in Applied Sciences in Biomedical and Communication Technologies (ISABEL), 2010 3rd International Symposium on, pp. 1-6, IEEE, 2010.

16. T. Dissanayake, M. R. Yuce and C. Ho, Design and evaluation of a compact antenna for implant-to-air UWB communication, IEEE Antennas Wireless Propagat. Lett., Vol. 8, pp. 153-156, 2009.

17. D. Anzai, K. Katsu, R. C. Santiago, Q. Wang, D. Plettemeier, J. Wang and I. Balasingham, Experimental evaluation of implant UWB-IR transmission with living animal for body area networks, IEEE Transactions on Microwave Theory and Techniques, Vol. 62, pp. 183-192, 2014.

18. Y. Morimoto, D. Anzai and J. Wang, Design of ultra wide-band low-band implant antennas for capsule endoscopy application, in Proc. 7th Intl. Symp. On Medical Information and Commun. Technol. (ISMICT), Tokyo, Japan, March 6-8, 2013, pp. 61-65.

19. S. M. Bunce, A. P. Moore and A. D. Hough, M-mode ultrasound: a reliable measure of trans-versus abdominis thickness?, Clinical Biomechanics, Vol. 17, pp. 315-317, 2002.

20. O. Akkus, A. Oguz, M. Uzunlulu and M. Kizilgul, Evaluation of skin and subcutaneous adipose tissue thickness for optimal insulin injection, Diabetes \& Metabolism, Vol. 3, pp. 3-8, 2012.

21. http://www.fcc.gov/oet/rfsafety/dielectric.html. 
22. https://www.itis.ethz.ch/virtual-population/tissue-properties/datab ase/dielectric-properties/.

23. M. Särestöniemi, C. Kissi, C. Pomalaza Raez, M. Sonkki, M. Hämäläinen and J. Iinatti, Propagation and UWB channel characteristics on human abdomen area, presented in EUCAP 2019, Krakow, Poland, April 2019.

24. M. Särestöniemi, C. Kissi;C. P-. Raez, T. Kumpuniemi;M. Sonkki, S. Myllymäki, M. Hämäläinen, and J. Iinatti, Measurement and simulation based study on the UWB channel characteristics on the abdomen area, Presented in ISMICT 2019 conference, Oslo, May 2019.

25. C. Kissi, M. Särestöniemi, T. Kumpuniemi, M. Sonkki, S. Myllymäki, M. N. Srifi, and C. P-. Raez, Low-UWB Antennas in Vicinity to Human Body, Presented in ISMICT 2019 conference, Oslo, Norway, May 2019.

26. M. Särestöniemi; C. Kissi; C. P-. Raez; M. Hämäläinen; and J. Iinatti, Impact of the antenna-body distance on the UWB on-body channel characteristics, Presented in ISMICT 2019 conference, Oslo, May, 2019.

27. T. Tuovinen, M. Berg and E. T. Salonen, Antenna Close to Tissue: avoiding Radiation Pattern Minima with an Anisotropic Substrate, IEEE Antennas and Wireless Propagation Letters, Vol. 13, pp. 1680-1683, 2014.

28. T. Kumpuniemi; M. Hämäläinen; K. Y. Yazdandoost and J. Iinatti, Human Tissue Type and Volume Effect on the On-Body UWB Antenna Matchings, 10th International Symposium on Medical Information and Communication Technology (ISMICT), pp. 1-5, 2016.

29. T. Tuovinen, M. Berg, K. Y. Yazdandoost and J. Iinatti, Ultra wideband loop antenna on contact with human body tissues, IET Microwaves, Antennas \& Propagation, Vol. 7, pp. 588-596, 2013.

30. M. Särestöniemi, C. Pomalaza-Raez, M. Berg, C. Kissi, M. Hämäläinen. J. Iinatti, In-Body Power Distribution for Abdominal Monitoring and Implant Communications Systems, accepted to be published in ISWCS2019, Oulu, Finland, August 2019.

31. M. Särestöniemi, C. P. Raez, C. Kissi, T. Kumpuniemi, M. Sonkki, M. Hämäläinen and J. Iinatti, Fat as a Propagation Medium in the Abdomen Area in the WBAN Applications, submitted to Bodynets 2019, Florence, Italy, October 2019.

Publisher's Note Springer Nature remains neutral with regard to jurisdictional claims in published maps and institutional affiliations.

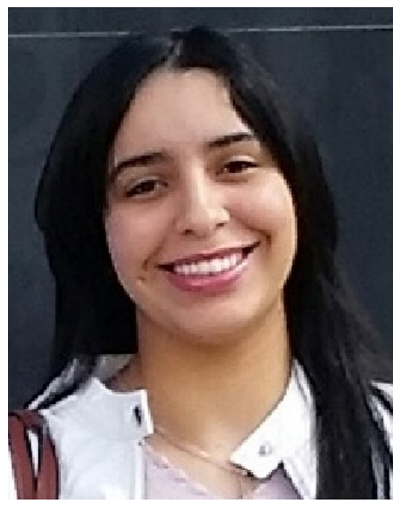

Chaïmaâ Kissi received her engineering Degree in 2015, from National School of Applied Sciences in Kenitra, from Ibn Tofail University, Morocco. She is currently a $\mathrm{PhD}$ student at Electronics and Telecommunication Systems Research Group, at National School of Applied Sciences (ENSA) in Kenitra. Her research focus is antenna design for medical applications.

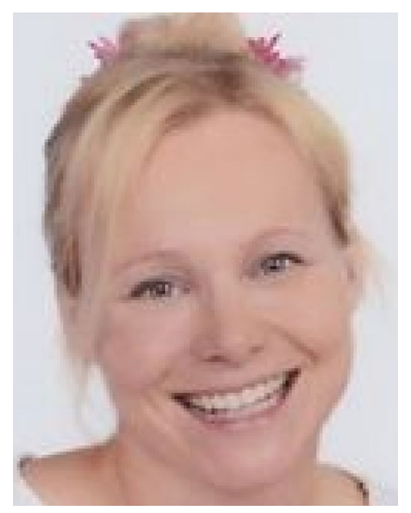

Mariella Särestöniemi received her M. Sc. (Tech.) and Lic. Sc. (Tech.) degrees in 2003 and 2005, respectively, from University of Oulu, Finland. Currently, she is a doctoral student at Centre for Wireless Communications at the University of Oulu. Her research interests are medical ICT, wireless body area networks, in- and on-body communications, simulation based channel modeling and measurements.

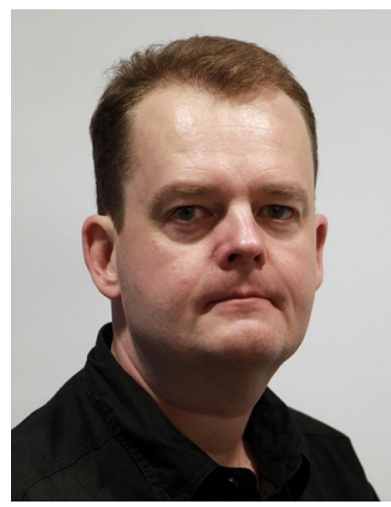

Timo Kumpuniemi received his M. Sc.(Tech.) and Lic. Sc. (Tech-) degrees in 2001 and 2008, respectively, from University of Oulu, Finland. He is at the moment working as a doctoral student at Centre for Wireless Communications at the University of Oulu. His current research interests cover wireless medical communications, biomedical engineering, wireless body area networks, visible light communications, radio engineering on various aspects and modulation methods. His teaching activities have been mainly on different fields of radio engineering.

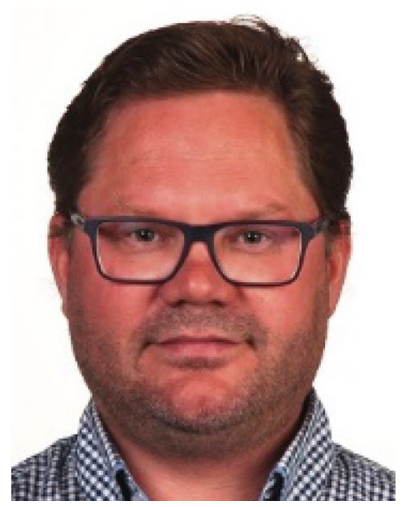

Marko Sonkki received his M.Sc. in electrical engineering from the Department of Electrical and Information Engineering, University of Oulu, Oulu, Finland, in 2004. In 2013, he received his $\mathrm{Ph} . \mathrm{D}$. in radio telecommunications engineering from the University of Oulu. The topic of his dissertation was wideband and multi-element antennas for wireless applications focusing on antenna design based on spherical and characteristic modes theories. He is currently a postdoctoral researcher with the Cen-

tre for Wireless Communications, University of Oulu. His current research interests include the design and analysis of wideband antennas, wideband multimode and full-duplex antennas, MIMO and diversity systems, and antenna array design, and mutual coupling between antenna elements, including millimeter waves. 


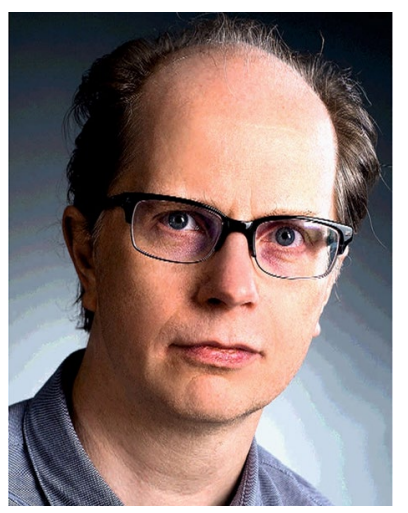

Sami Myllymäki is with Microelectronics Research Unit at the University of Oulu, Finland. He has M.Sc. and D.Sc degrees and he is currently working as research group leader and adjunct professor at the University of Oulu. He has led several large industrial research projects and his teaching includes electronics packaging technology.

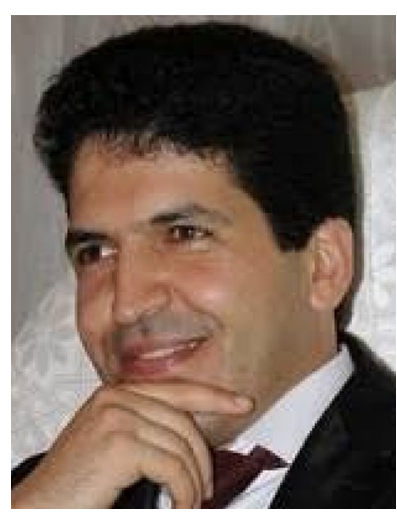

Mohamed Nabil Srifi was born in Sidi Redouane Ouezzane, Morocco, in January 1978. He received the Licence de Physique degree in electronics from Ibn Tofail University, Kenitra, Morocco, in 1999, and the Deep Higher Studies Diploma DESA degree in telecommunications systems and the Ph.D. degree in electrical engineering from Abdelmalek Essaadi University, Tetuan, Morocco, in 2004 and 2009 , respectively. He is currently an Assistant Professor of electrical engineering at Ibn
Tofail University, Morocco. His research interests include biological effects of radiofrequency and microwave, bio-electromagnetics, biomedical engineering and antenna design. He holds two patents on antennas for ultra-wide band applications. Dr. Nabil Srifi is a recipient of national and international awards, and is the Vice-secretary of the Moroccan Association of Electricity, Electronics and Computers Engineering (AEECE).

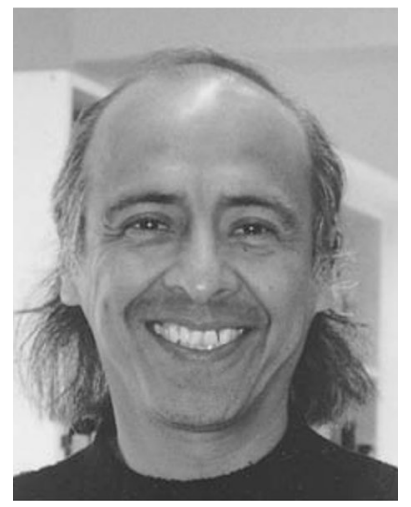

Carlos Pomalaza-Ráez (M'80SM'06) received the B.S.M.E. and B.S.E.E. degrees from Universidad Nacional de Ingeniería, Lima, Peru, in 1974, and the M.S. and Ph.D. degrees in electrical engineering from Purdue University, West Lafayette, IN, USA, in 1977 and 1980, respectively. $\mathrm{He}$ is an electrical engineering Professor at Purdue University, Fort Wayne, Indiana, USA. He has been a faculty member at the University of Limerick, Limerick, Ireland, and at Clarkson University, Potsdam,

NY, USA. He has also been a Member of the Technical Staff at the Jet Propulsion Laboratory, California Institute of Technology, Pasadena, CA, USA. 